\title{
Phosphonofluoresceins: synthesis, spectroscopy, and applications
}

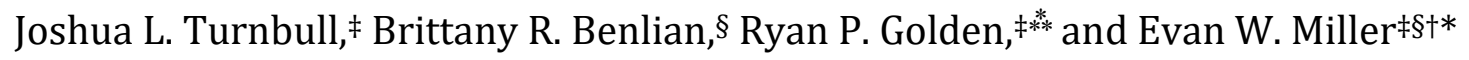 \\ Departments of $¥$ Chemistry and \$Molecular \& Cell Biology and †Helen Wills Neuroscience Institute. University of \\ California, Berkeley, California 94720, United States
}

\begin{abstract}
Xanthene fluorophores, like fluorescein, have been versatile molecules across diverse fields of chemistry and life sciences. Despite the ubiquity of 3-carboxy and 3-sulfuonofluorescein for the last 150 years, to date, no reports of 3phosphonofluorescein exist. Here, we report the synthesis, spectroscopic characterization, and applications of 3phosphonofluoresceins. The absorption and emission of 3-phosphonofluoresceins remain relatively unaltered from the parent 3-carboxyfluorescein. 3-phosphonofluoresceins show enhanced water solubility compared to 3-carboxyfluorescein and persist in an open, visible light-absorbing state even at low $\mathrm{pH}$ and in low dielectric media while 3-carboxyfluoresceins tend to lactonize. In contrast, the spirocyclization tendency of 3-phosphonofluoresceins can be modulated by esterification of the phosphonic acid. The bis-acetoxymethyl ester of 3-phosphonofluorescein readily enters living cells, showing excellent accumulation $(>6 x)$ and retention $(>11 x)$, resulting in a nearly 70 -fold improvement in cellular brightness compared to 3 carboxyfluorescein. In a complementary fashion, the free acid form of 3-phosphonofluorescein does not cross cellular membranes, making it ideally suited for incorporation into a voltage-sensing scaffold. We develop a new synthetic route to functionalized 3-phosphonofluoresceins to enable the synthesis of phosphono-voltage sensitive fluorophores, or phosVF2.1.Cl. Phosphono-VF2.1.Cl shows excellent membrane localization, cellular brightness, and voltage sensitivity $(26 \%$ $\Delta \mathrm{F} / \mathrm{F}$ per $100 \mathrm{mV}$ ), rivalling that of sulfono-based $\mathrm{VF}$ dyes. In sum, we develop the first synthesis of 3-phosphonofluoresceins, characterize the spectroscopic properties of this new class of xanthene dyes, and utilize these insights to show the utility of 3-phosphonofluoresceins in intracellular imaging and membrane potential sensing.
\end{abstract}

\section{Introduction}

Since the original synthesis of fluorescein in $1871,{ }^{1}$ this versatile molecule remains one of the most widely utilized fluorophores in biology, medicine, and chemical biology. Fluorescein labelled antibodies were the first immunofluorescent stains, ${ }^{2}$ and reagents such as fluorescein isothiocyanate, or FITC, remain ubiquitous for the preparation of fluorescent biological conjugates. ${ }^{3}$ One of the few fluorophores FDA-approved for use in humans, sodium fluorescein has found clinical uses in ophthalmology, ${ }^{4-5}$ and more recently, neurosurgery. ${ }^{6}$ A staple in the chemical biology community, countless fluorescein-derived probes and sensors have been reported over the years.-9 Design of such probes often take advantage of the ability to modulate fluorescence by substitution at the phenolic oxygen, control of spirocyclization, or changes in the rate of photoinduced electron transfer (PeT).8, 10-12 For example, appending BAPTA, a calcium chelator, to fluoresceins is a common strategy that makes use of PeT to modulate fluorescence and has enabled probing of intracellular calcium dynamics in neurons and brain tissue with high sensitivity and spatiotemporal resolution. ${ }^{13-15}$

The wide utility of fluorescein and related xanthene dyes is due, in part, to its high brightness and wide range of colors available with simple modifications to the terminal and bridgehead atoms of the xanthene fluorophore core. Replacement of the terminal oxygen atoms with substituted nitrogen results in another class of xanthene fluorophores rhodamines. Spectral properties of rhodamines can be finetuned by varying the amine substitution, ${ }^{16}$ for example, four-membered azetidines substantially improve brightness and photostability. ${ }^{17}$ Replacement of the $10^{\prime}$ oxygen atom with carbon, ${ }^{18-19}$ silicon, ${ }^{20-23}$ phosphorous, ${ }^{24-26}$ or sulfur ${ }^{27}$ red-shifts excitation and emission wavelengths, reducing phototoxicity, autofluorescence, and improving tissue penetration for in vivo imaging.

By comparison, substitution of the pendant carboxylate of fluoresceins had remained relatively underexplored. Substitution at the 3 position restricts free rotation of the meso ring, improving the fluorescence quantum yield. ${ }^{10}$ The chemical identity of the substitution at the 3 position can have profound effects on the properties of fluoresceins and related xanthenes. Fluoresceins spirocyclize at low $\mathrm{pH}$ or in low dielectric mediums to a non-fluorescent lactone, and this is often the basis for design of fluorogenic probes. ${ }^{12}$ Substitution of the 3-carboxylate for hydroxymethyl, aminomethyl, or mercaptomethyl nucleophiles tunes the spirocyclization equilibrium of various rhodamines. ${ }^{28-30}$ This led to the development of spontaneously blinking fluorophores for single molecule localization microscopy. On the other hand, sulfono-fluoresceins (Scheme 1), bearing a sulfonate at the 3 position, do not spirocyclize and have improved water solubility: properties that have been instrumental in the design of voltage sensitive fluorophores (VF dyes). ${ }^{31-34}$

While fluoresceins with acidic substituents at the 3 position have been ubiquitous in the literature for some time (3-sulfonofluorescein was reported a mere 13 years ${ }^{35}$ after 3 -carboxyfluorescein ${ }^{1}$ ), we were somewhat surprised to find no report describing 3-phosophono-fluorescein, which possesses the biologically relevant acidic phosphonate group (Scheme 1). We were curious to explore this 
Scheme 1. Unique properties of phosphonofluorescein

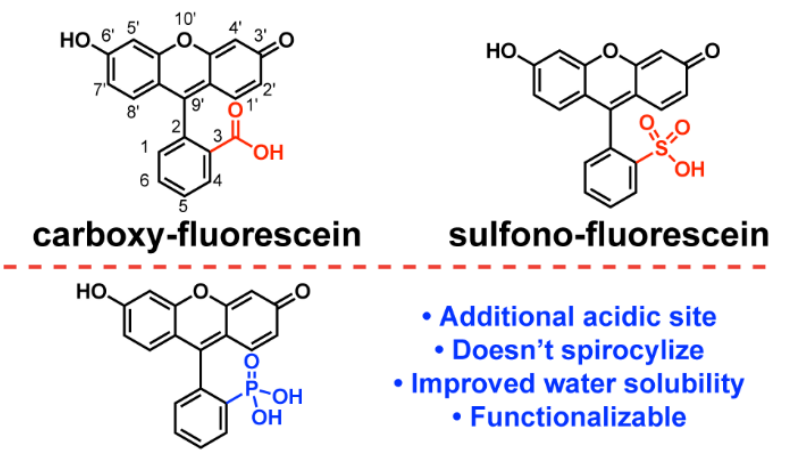

\section{phosphono-fluorescein}

unreported class of fluoresceins and envisioned that 3phosphonofluoresceins might have unique properties compared to 3-carboxyfluoresceins. For example, the two acidic sites on phosphonates - the first $\mathrm{pK}_{\mathrm{a}}$ above sulfonic acid but below carboxylic acid, and a second $\mathrm{pK}_{\mathrm{a}}$ near physiological $\mathrm{pH}^{36}$ - might provide opportunities for functionalization. The persistent ionization of phosphonates at physiological $\mathrm{pH}$ might also enhance water solubility compared to 3-carboxyfluoresceins. Here, we report the first synthesis of 3-phosphonofluoresceins, characterize the spectral properties of this new class of fluorophore, and exploit the properties of 3phosphonofluoresceins for two orthogonal live-cell imaging applications.

\section{Results}

Synthesis of 3-phosphonofluoresceins

Substituting the carboxylate functionality of fluoresceins poses an inherent synthetic challenge. Attempts to displace fluoride from 2-fluorobenzaldehyde with triethylphosphite, in a fashion analogous to the synthesis of 3sulfonofluorescein precursors, ${ }^{32,37}$ resulted in no reaction. However, Ni-mediated catalysis ${ }^{38-39}$ enabled access to arylphosphonic ester $\mathbf{2}$ from 2-bromobenzaldehyde $\mathbf{1}$ in $65 \%$ yield (Scheme 2). A slight excess of triethyl phosphite is required due to undesired oxidation of the phosphite to the corresponding phosphate at elevated temperature. A weak nitrogen flow is also prudent to remove the generated ethylbromide. This approach enabled facile access to up to $10 \mathrm{~g}$ quantities of $\mathbf{2}$ in one step from simple starting reagents. Hydrolysis to phosphonic acid $\mathbf{3}$ was performed in concentrated $\mathrm{HCl}$ under refluxing conditions to give the free acid in $87 \%$ yield. While the diethyl ester precursor (2) could be carried directly into the condensation with resorcinols to make 3-phosphonofluoresceins (with hydrolysis of diethylphosphonate occurring in situ), we observed improved yields and simpler purification when using free phosphonic acid (3). Condensation of $\mathbf{3}$ with the corresponding resorcinol in neat methanesulfonic acid gave dihalogenated phosphonofluoresceins 4 and 5 . Nonhalogenated phosphonofluorescein (6) could also be prepared via this route, but cleaner conversion was observed with $85 \%$ phosphoric acid at the expense of a longer reaction time.
Scheme 2. Synthesis of phosphonofluoresceins

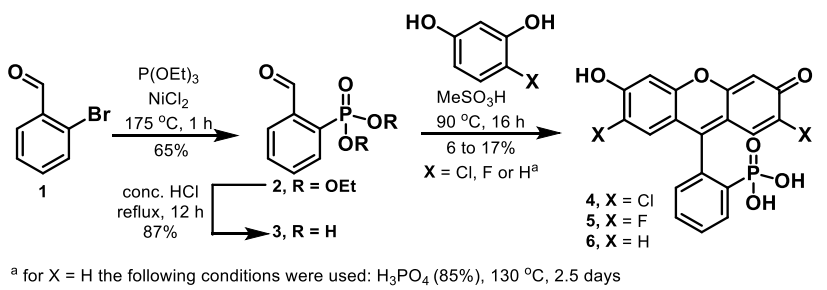

The purification of crude phosphonofluoresceins was difficult, owing to the high polarity of the water-soluble dyes. Careful trituration of the crude reaction isolate with mixtures of cold methanol/isopropanol or methanol/acetonitrile enabled isolation of pure dyes (Supporting Info). This approach negated the need for costly and low throughput reverse phase chromatographic techniques (such as HPLC), but came at the cost of reduced isolated yields, ranging from 6 to $17 \%$. It is notable that this synthetic route provides similar yields to those observed with the analogous sulfonated derivatives (Supporting Info) and low yields/non-trivial purifications are commonly encountered with such reactions.

\section{Spectroscopic Characterization of 3-phosphonofluorescein}

To examine the influence of phosphonate substitution on fluorescein, we evaluated the spectroscopic properties of 3phosphonofluoresceins (4 - 6) compared to traditional 3carboxy- and 3-sulfono- fluoresceins. In $0.1 \mathrm{M} \mathrm{NaOH}_{(\mathrm{aq})} 2$ ', 7 'dichloro-3-phosphonofluorescein (pF.Cl, 4) absorbs at 498 $\mathrm{nm}$ and emits at $517 \mathrm{~nm}$, demonstrating a very slight hypsochromic shift relative to 2',7'-dichloro-3carboxyfluorescein $(502 \mathrm{~nm} / 523 \mathrm{~nm}) .{ }^{40}$ The sulfo derivative, 2',7'-dichloro-3-sulfonofluorescein (sF.Cl), however has a slight bathochromic shift and absorbs at 509 $\mathrm{nm}$ and emits at $526 \mathrm{~nm}$. These small shifts are likely due to slight inductive differences from the meso ring. Since the meso ring and the xanthene are orthogonal to one another, there should be minimal ground state interactions between the two. As a result, the Stokes shift, extinction coefficients, and quantum yields show only minor variability across the series (Table 1). One large change is the improved water solubility; PF.Cl (4) is almost twice as soluble as 2',7'dichloro-3-carboxyfluorescein, and slightly less soluble than sF.Cl (Table 1).

\section{pH titration of 3-phosphonofluoresceins}

Fluorescein can exist in cationic, neutral, anionic or dianionic forms, making absorption and fluorescence of fluoresceins strongly $\mathrm{pH}$ dependent. ${ }^{41-42}$ Halogenated $\left(2^{\prime}, 7^{\prime}\right.$ dichloro or difluoro) fluoresceins have lower phenolic $\mathrm{pK}_{\mathrm{a}}$ values than the corresponding unhalogenated fluorescein, making dichloro- and difluoro- fluoresceins less sensitive to biologically relevant $\mathrm{pH}$ fluctuations. ${ }^{40,43}$ In order to assess the effect of meso substitution on the pH sensitivity, we titrated 3-carboxy, 3-sulfono and 3-phosphonodichlorofluoresceins from pH 2.3 to 9.8 (Figure 1a, d, and g). Transition to the dianion can be monitored by measuring the increase in absorption at $\lambda_{\max }$ with respect to increasing $\mathrm{pH}$ (Figure 1b, e, and h). The phenolic $\mathrm{pK}_{\mathrm{a}}$ of all three dichlorofluoresceins is 4.5 , suggesting substitution at the 3 position has little effect on formation of the dianion (Figure 1c, f, and i). 

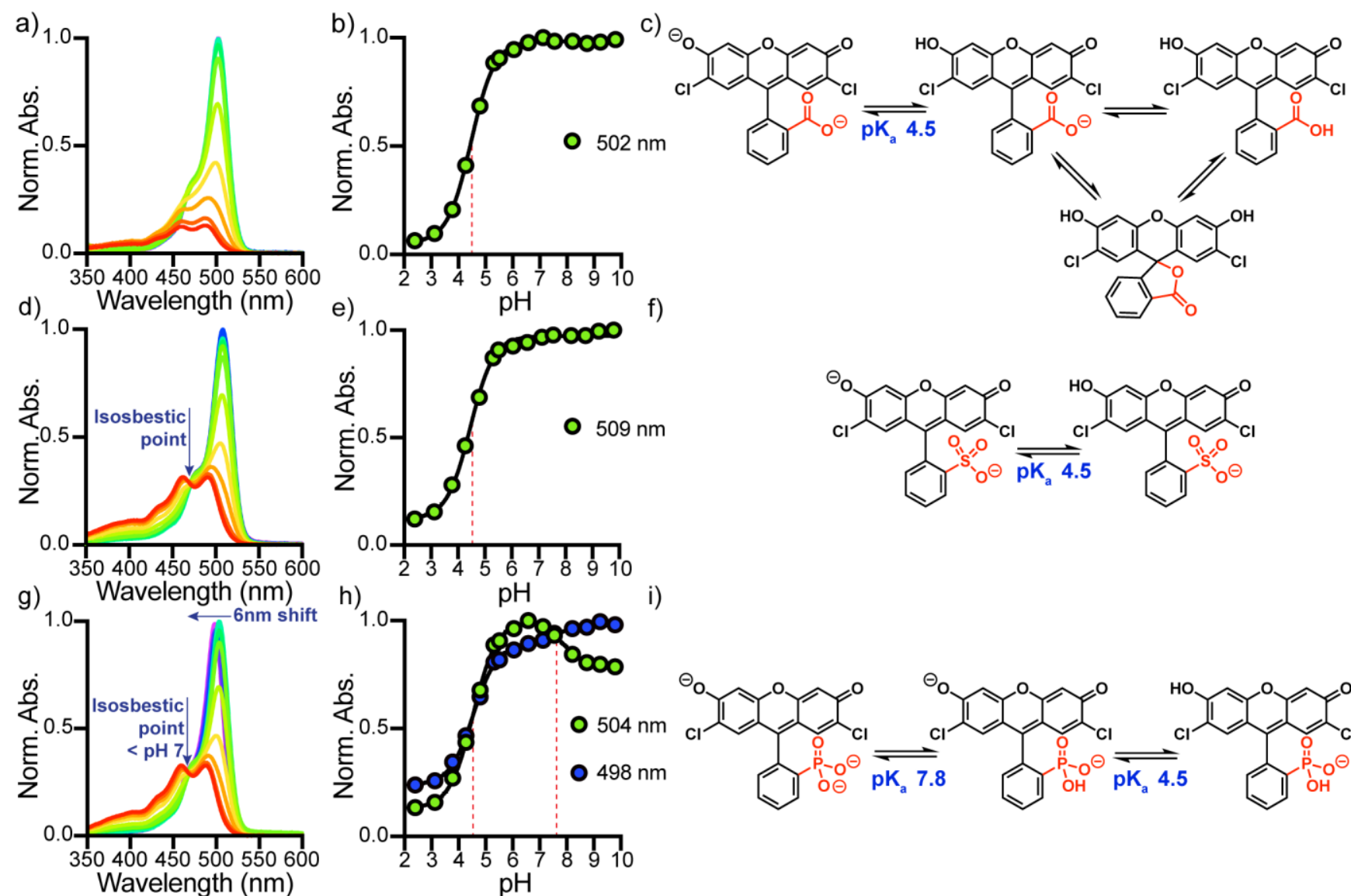

Figure 1. Spectroscopic characterization of the $\mathrm{pH}$ dependence of dichlorofluoresceins. Normalized absorbance spectra and corresponding plots of normalized absorbance vs. $\mathrm{pH}$ at $\lambda_{\max }$ for carboxy- $(\mathrm{a}, \mathrm{b})$, sulfono- $(\mathrm{d}$, e) and phosphono- (g, h) dichlorofluoresceins. Spectra were recorded in $10 \mathrm{mM}$ buffered solutions (see supporting information) containing $150 \mathrm{mM}$ NaCl from $\mathrm{pH} 2.4$ (red) to 9.8 (magenta) at a dye concentration of $2 \mu \mathrm{M}$. Titration curves fit to sigmoidal dose response curves (solid black) enabled $\mathrm{pK}_{\mathrm{a}}$ determination (dashed red). Error bars represent \pm SEM for $\mathrm{n}=3$ independent determinations and if not visible are smaller than the marker. Summary of $\mathrm{pH}$ equilibria with determined pKa values for carboxy- (c), sulfono- (f) and phosphono- (i) dichlorofluoresceins.

Table 1. Properties of fluoresceins

\begin{tabular}{|c|c|c|c|c|c|c|c|}
\hline Dye & $\mathbf{R}$ & $\mathbf{X}$ & $\lambda_{\max } / \mathbf{n m}^{\mathbf{a}}$ & $\lambda_{\mathrm{em}} / \mathbf{n m}^{\mathrm{a}}$ & $\varepsilon / \mathbf{M}^{-1} \mathbf{c m}^{-1 \mathbf{a}, \mathrm{b}}$ & $\Phi_{\mathrm{fl}}{ }^{\mathrm{a}}$ & Solubilityc \\
\hline fluorescein & $-\mathrm{CO}_{2} \mathrm{H}$ & $-\mathrm{H}$ & 491 & 514 & 88,000 & 0.92 & --- \\
\hline 2',7'-dichloro-3-carboxy-fluorescein & $-\mathrm{CO}_{2} \mathrm{H}$ & $-\mathrm{Cl}$ & 502 & 523 & 86,000 & 0.94 & 1 \\
\hline $\begin{array}{r}\text { 2',7'-dichloro-3-sulfonofluorescein } \\
\text { (sF.Cl) }\end{array}$ & $-\mathrm{SO}_{3} \mathrm{H}$ & $-\mathrm{Cl}$ & 509 & 526 & 87,000 & 0.89 & 3.1 \\
\hline $\begin{array}{r}\text { 2',7'-dichloro-3- } \\
\text { phosphonofluorescein (pF.Cl, 4) }\end{array}$ & $-\mathrm{PO}_{3} \mathrm{H}_{2}$ & $-\mathrm{Cl}$ & 498 & 517 & 88,000 & 0.90 & 1.8 \\
\hline $\begin{array}{r}\text { 2',7'-difluoro-3- } \\
\text { phosphonofluorescein (pF.F, 5) }\end{array}$ & $-\mathrm{PO}_{3} \mathrm{H}_{2}$ & $-F$ & 488 & 508 & 84,000 & 0.94 & --- \\
\hline 3-phosphonofluorescein (pF.H, 6) & $-\mathrm{PO}_{3} \mathrm{H}_{2}$ & $-\mathrm{H}$ & 487 & 508 & 75,000 & 0.99 & --- \\
\hline
\end{tabular}

a in $0.1 \mathrm{M} \mathrm{NaOH}_{(\mathrm{aq})}$, relative to fluorescein. ${ }^{\mathrm{b}}$ At max absorption. ${ }^{\mathrm{c}}$ measured in PBS relative to 2',7'-dichlorofluorescein

The $\mathrm{pK}_{\mathrm{a}}$ values for non-halogenated, 3phosphonofluorescein $\left(6, \mathrm{pK}_{\mathrm{a}}=6.4\right)$ and fluorinated 3phosphonofluorescein $\left(5, \mathrm{pK}_{\mathrm{a}}=4.8\right)$ also closely match the $\mathrm{pK}_{\mathrm{a}}$ value of the analogous 3-carboxy analog (Figures S2 and S3). ${ }^{43}$ Unique to 3-phosphonofluoresceins, after deprotonation to the dianion, a $5 \mathrm{~nm}$ hypsochromic shift is observed as $\mathrm{pH}$ continues to increase (Figure 1g, Figure S2a and c). This likely results from formation of a trianion
(Figure 1i) due to the extra acidic site on the phosphonate and quantification of this shift with 4 (pF.Cl) reveals a $\mathrm{pK}_{\mathrm{a}}$ of 7.8 - in the typical range of acidities for aryl phosphonic acids. ${ }^{34}$

Cyclization tendency of 3-phosphonofluoresceins

In the neutral form, carboxy fluoresceins spirocyclize to a colorless, non-fluorescent lactone (Figure 1c) whereas 
Scheme 3. Synthesis of phosphonofluorescein acetoxy methyl esters and ethers.
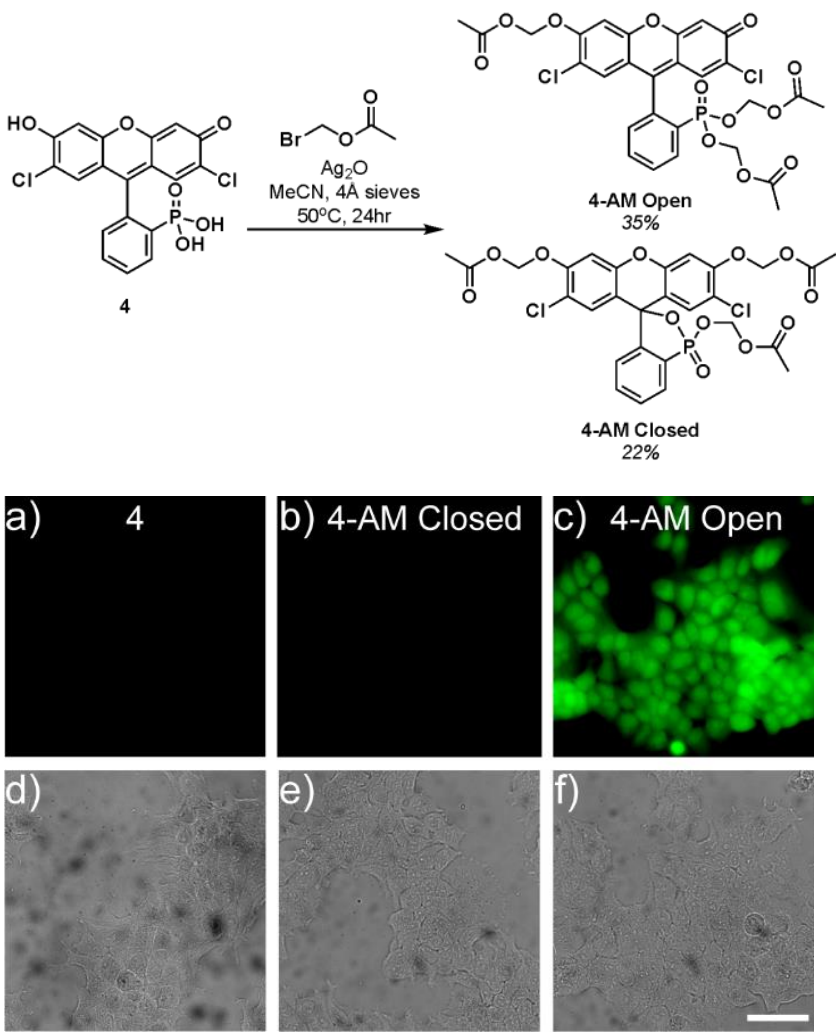

Figure 2. Cell permeability of phosphonofluoresceins. Widefield fluorescence (a-c) and DIC (d-f) images of HEK cells stained with $500 \mathrm{nM} 4$ (a,d), 4-AM closed (b,e) and 4-AM open (c,f) for $20 \mathrm{~min}$ at $37^{\circ} \mathrm{C}$. Cells were washed once with HBSS prior to imaging. Scale bar is $50 \mu \mathrm{M}$.

3-sulfono-fluoresceins do not (Figure 1d-f). Both sulfono- and phosphono-dichlorofluoresceins have a clear isosbestic point between $\mathrm{pH} 2.3$ and 6.8 (Figure 1d and g), resulting from the interconversion of the anionic quinoid and dianion. The same isosbestic point is not observed with 3-carboxy dichlorofluorescein as absorption continuously decreases with $\mathrm{pH}$ due to spirocyclization to the neutral lactone at low $\mathrm{pH}$ (Figure 1a). The observation that carboxy-fluoresceins spirocyclize whereas sulfono- and phosphono-fluoresceins do not can be rationalized by the difference in $\mathrm{pK}_{\mathrm{a}}$ values. The 3-substituents on the latter two are strongly acidic, with $\mathrm{pK}_{\mathrm{a}}$ values lower than protonation of the xanthene to the cationic form (Figure S3c), and thus the neutral form favors an open zwitterion. The carboxylate, however, has a higher $\mathrm{pK}_{\mathrm{a}}$, so a significant portion of the neutral form exists as a closed lactone. ${ }^{41}$ Fluorescein can also spirocyclize in low dielectric media and thus doesn't absorb light in the visible region (Figure S4a,b, red trace). In low dielectric media, both 3phosphono- (Figure S4d-f) and 3-sulfono-fluoresceins (Figure S4c) possess absorbance profiles similar to the protonated xanthene in the open form. Moving from high to low dielectric, we observe an apparent increase in the $\mathrm{pK}_{\mathrm{a}}$ of the phenolic oxygen but no tendency to spirocyclize into the colorless lactone.
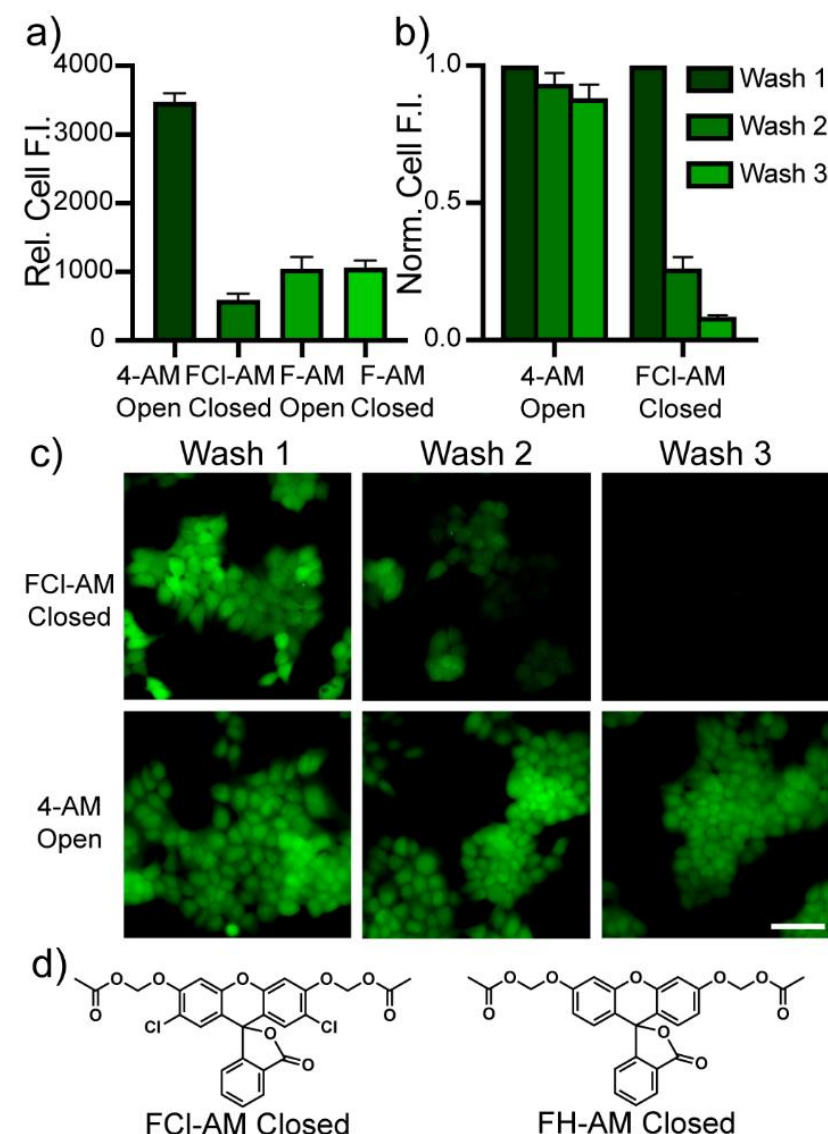

Wash 2

Wash 3
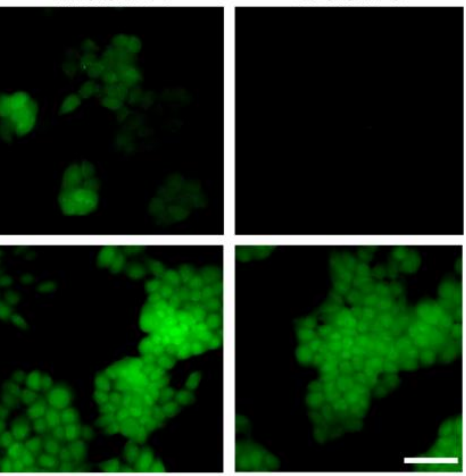

FCl-AM Closed

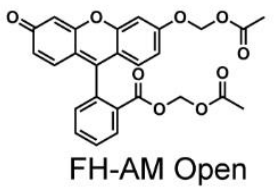

Figure 3. Cellular retention of fluoresceins. (a) Comparison of the relative brightness of fluorescein AMs in HEK cells. (b) normalized intensity and (c) fluorescence images of 4-AM Open and $\mathrm{FCl}-\mathrm{AM}$ Closed loaded onto HEK cells at $500 \mathrm{nM}$ in HBSS for 20 min. Cells were sequentially washed with fresh HBSS and changes in fluorescence intensity were measured by means of fluorescence microscopy. All dyes were loaded at $500 \mathrm{nM}$ in HBSS for $20 \mathrm{~min}$ at $37^{\circ} \mathrm{C}$. Error bars in (a) and (b) are \pm SEM for $\mathrm{n}=4$ coverslips. Scale bar is $50 \mu \mathrm{m}$. (d) Chemical structures of carboxyfluorescein AMs.

\section{Cell permeability and retention}

Acetoxy methyl (AM) ethers are commonly employed to deliver anionic fluorophores and small molecules into cells. ${ }^{44}$ The high $\mathrm{pK}_{\mathrm{a}}(\sim 13)$ of the formaldehyde hydrate leaving group provides chemical and hydrolytic stability, therefore AM ether hydrolysis relies on endogenous cellular esterases. ${ }^{45}$ In the context of fluorescein, this uncaging process is fluorogenic; hydrolysis of the first AM ether releases the dye from its closed, colorless lactone form and hydrolysis of the second AM ether provides the negatively charged phenolate responsible for strong fluorescence. This fluorogenicity has resulted in the widespread use of fluorescein AMs as cell viability reagents and has enabled the intracellular delivery of numerous fluorescein-derived probes. Despite their widespread use, carboxy fluoresceins are rapidly effluxed out of cells, hindering the long-term imaging of live cells. ${ }^{46-48}$ We considered whether the 
Scheme 4. Synthesis of phosphono-VoltageFluors.

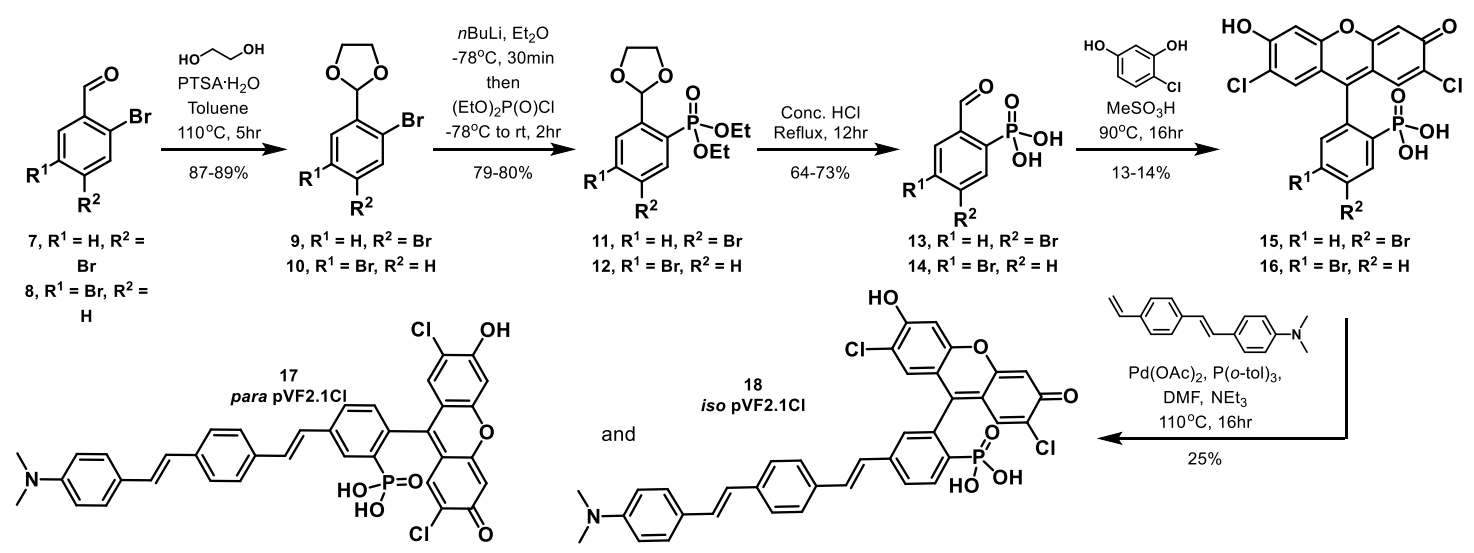

improved water solubility and lower $\mathrm{pK}_{\mathrm{a}}$ of 3phosphonofluoresceins would improve intracellular retention, since this charged group must be masked in some way in order to cross the lipid bilayer. While 3-sulfonofluoresceins also possess high water solubility and low $\mathrm{pK}_{\mathrm{a}}$ values, sulfonic esters are potent electrophiles, making them inherently unstable and difficult to chemically mask for intracellular delivery. ${ }^{49}$ On the other hand, phosphonates are commonly masked with biologically labile protecting groups, such as AM esters, to deliver phosphonate containing molecules into cells. . $^{50}$ This approach is commonly incorporated into the design of nucleotide (or nucleoside phosphate) prodrugs. ${ }^{53-54}$

Treatment of 3-carboxy-fluoresceins with bromomethyl acetate in the presence of $\mathrm{Ag}(\mathrm{I})$ in $\mathrm{MeCN}$, results predominantly in the closed, non-fluorescent, lactonized form with two phenolic AM ethers, although a small amount of the open AM ether/ester can be isolated. ${ }^{45}$ Owing to the tendency to not spirocyclize, the opposite selectivity was observed with PF.Cl (4), where the open form (4-AM open) was the major product, and the cyclized form (4-AM closed) was the minor product (Scheme 3). In buffered saline (Hank's balanced salt solution, HBSS), 4-AM open has absorption centered at $467 \mathrm{~nm}$, and emission profiles characteristic of a singly alkylated xanthene ether (Figure S5a). No hydrolysis was observed after several hours of incubation in HBSS at $37{ }^{\circ} \mathrm{C}$ (Figure S6). Incubation in strong base, or in the presence of porcine liver esterase (PLE), however, resulted in a $\sim 30 \mathrm{x}$ fold increase in fluorescence (Figure S6 and S5a), demonstrating effective release of the free dye, behaving in the same way as the analogous carboxy-fluorescein AM (Figure S5e). While the closed, 3-carboxy fluorescein AMs absorb no visible light in HBSS (Figures S5c,d), 4-AM closed, with an absorption maximum at $443 \mathrm{~nm}$, displays a spectrum (Figure S5b) similar to that of the cationic species observed at low $\mathrm{pH}$ (Figure S2b), suggesting the 4-AM closed is in an open, zwitterionic form. Subsequent incubation of 4-AM closed at $37{ }^{\circ} \mathrm{C}$ in HBSS for 2 hours results in a loss of any visible absorption (Figure S5b) along with a decrease in $\mathrm{m} / \mathrm{z}$ corresponding to loss of a single AM group (Figure S7). This suggests that in this form, the phosphono ester is prone to facile hydrolysis. The ${ }^{31} \mathrm{P}$ NMR chemical shift of 4-AM closed is significantly downfield (30.3 ppm, Spectrum S23) relative to 4-AM open (14.3 ppm, Spectrum S20), likely a result of increased electrophilicity and thus confers decreased hydrolytic stability of 4-AM closed.

Unsurprisingly, 4, which contains no AM esters, is cell impermeable and no uptake into HEK293T (HEK) cells was observed by fluorescence microscopy after 20 minutes of incubation (Figure 2a,d). The same is true for 4-AM closed suggesting the phosphonoester is rapidly hydrolyzed and the resulting negative charge precludes the ability to diffuse across the cell membrane (Figure 2b,e). The strong cellular fluorescence from cells treated with 4-AM open indicates a high degree of cell permeability followed by fluorogenic uncaging (Figure 2c,f). Compared to 3-carboxyfluorescein AM derivatives, 4-AM open has between 3.5 to 6 -fold increase in cellular fluorescence intensity compared to $\mathrm{FCl}$ and FH-AMs (both open and closed) at $500 \mathrm{nM}$ in HEK cells (Figure 3a), enabling the phosphono derivative to be used at much lower concentrations. In fact, we saw reasonable fluorescence intensity at $100 \mathrm{nM}$ concentrations, whereas carboxy fluoresceins are often loaded in the $\mu \mathrm{M}$ range. ${ }^{43}$

We postulated the increased cellular fluorescence intensity of 3-phosphonofluoresceins may result from improved cellular retention compared to 3carboxyfluoresceins. Serial washing of cells loaded with FClAM $\left(2^{\prime}, 7^{\prime}\right.$-dichloro-3-carboxyfluorescein $)$ results in a dramatic loss of fluorescence and after 3 washes cellular fluorescence levels are 8\% of original intensities (Figure $\mathbf{3 b}, \mathbf{c})$. Conversely, with 4-AM open, cellular fluorescence intensity levels remain at $89 \%$ of the original values, even after 3 washes (Figure $\mathbf{3 b}, \mathbf{c}$ ), thereby demonstrating an almost 70 fold increase in fluorescence intensity compared to cells stained with FCl-AM. The enhanced cellular retention of 3-phosphonofluoresceins expands the scope of use for prolonged imaging in living cells.

We then incubated HEK cells labelled with FCl-AM closed, 4-AM open and calcein AM (a multiply carboxylated fluorescein derivative with excellent cellular retention $)^{48,55}$ in DMEM for up to 60 minutes prior to imaging. Carboxy fluorescein was rapidly effluxed and no fluorescence was seen after the 0 min time point, whereas phosophonofluorescein appeared to efflux at a much slower rate, and almost half the intracellular fluorescence was retained after an hour (Figure S10b). Anionic transporters such as multidrug resistant-associated proteins (MRP) have been implicated in the efflux of fluorescein from cells and MRP inhibitors such as MK-571 improve retention and 


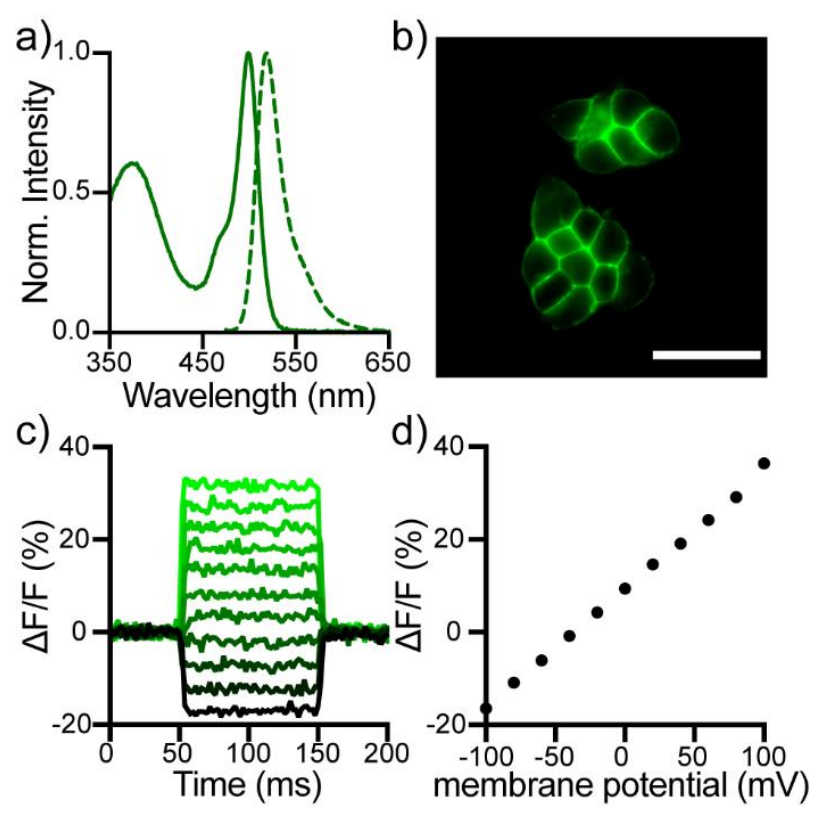

Figure 4. Cellular and in vitro characterization of phosphonated VoltageFluors. (a) Normalized absorbance (solid line) and fluorescence emission (dashed line) spectra of para phosVF2.1Cl (17) in $0.1 \mathrm{M} \mathrm{NaOH}_{(\mathrm{aq})}$. (b) HEK cells stained with $250 \mathrm{nM}$ para phosVF2.1Cl (17). Scale bar is $40 \mu \mathrm{m}$. (c) Plot of the fractional change in fluorescence of para phosVF2.1Cl (17) vs time for $100 \mathrm{~ms}$ hyper- and depolarizing steps $( \pm 100$ $\mathrm{mV}$ in $20 \mathrm{mV}$ increments) for single HEK cells under whole-cell voltage-clamp mode. (d) plot of $\Delta \mathrm{F} / \mathrm{F}$ vs final membrane potential, revealing a voltage sensitivity of approximately $26 \%$ per $100 \mathrm{mV}$. Error bars are \pm SEM for $\mathrm{n}=17$ cells. If not visible, error bars are smaller than the marker.

accumulation of dyes. ${ }^{56-58}$ Incubation of stained HEK cells in DMEM containing MK-571 $(50 \mu \mathrm{M})$ reduces the rate of dichlorofluorescein efflux after 15 minutes (Figure S10d), however almost all cellular fluorescence was still lost after 60 minutes (Figure S10c). On the contrary phosphonofluorescein efflux was almost completely inhibited by MK-571: no change in cellular fluorescence intensity was observed after 60 minutes incubation in the presence of MK-571 (Figure S10). One could imagine circumstances where moderate efflux of a fluorophore could prove beneficial, such as improving contrast when labelling intracellular structures. On the other hand, phosphonofluorescein efflux can be readily inhibited with the addition of MK-571 for situations where efflux would be undesirable.

\section{Voltage sensing with phosphonofluoresceins}

The cellular uptake of 3-phosphonofluoresceins, like 4, can be readily controlled by esterification of the 3phosphonate, with the free phosphonic acid showing excellent exclusion from cells. Because of the tunable cellular permeability profile, high water solubility, and lack of spirocyclization, we hypothesized that 3phosphonofluoresceins could be readily incorporated into a voltage-sensitive fluorophore (VoltageFluor) configuration, which employs voltage-sensitive photoinduced electron transfer (PeT) from a lipophilic, electron-rich, anilinecontaining phenylene vinylene molecular wire into a fluorophore. ${ }^{34}$ These VoltageFluors have primarily relied on 3-sulfonofluoresceins to prevent dye internalization and ensure proper orientation within the plasma membrane. ${ }^{32,}$ 59

The voltage-sensing molecular wire domains of VFs are typically installed via Heck coupling to fluoresceins, making use of a 4' or 5' halogen. Since we also require a halogen handle to install the phosphonate, we first protected 2,4and 2,5-dibromo benzaldehydes with ethylene glycol and used the corresponding acetals to direct lithium-halogen exchange with $n$-butyllithium exclusively to the ortho position (Scheme 4). Slow addition of diethyl chlorophosphate and subsequent hydrolysis in concentrated acid yielded 4- and 5-bromo phosphonobenzaldehdyes (13 and 14) which were condensed with 4chlororesocinol to the corresponding 2',7'-dichloro-3phosphonofluoresceins. The bromine functional group enabled Pd-catalyzed Heck coupling to a styrene molecular wire to produce para and iso phosVFs (17 and 18); however only limited conversion occurred, and significant amounts of dehalogenated and unreacted dye were observed. We initially suspected this could be a result of the presence of the phosphonic acid functional group, but Pd-catalyzed cross coupling of phosphonate-containing precursor 13 and the same styrene resulted in a much greater $73 \%$ yield (SI compound 19). The desired phosVFs were, however, readily purified by reverse phase silica chromatography to give the desired products in 25\% yield.

Both para and iso phosVFs possess absorbance and emission spectra nearly identical to pF.Cl (4), with the addition of an absorbance band at around $370 \mathrm{~nm}$, corresponding to the aniline-containing molecular wire (Figure 4a, Figure S11). Both phosVF dyes localize to cellular membranes of HEK293T cells (Figure 4b, Figure S12) and are voltage sensitive (Figure 4c and d, Figure S13). Patch clamp electrophysiology coupled with fluorescence microscopy reveal that para phosVF2.1Cl has a voltage sensitivity of $26 \% \Delta \mathrm{F} / \mathrm{F}$ per $100 \mathrm{mV}$ (Figure 4c,d), roughly the same sensitivity as the sulfonated analog, VF2.1Cl (24\%). 31,60 The same trend was seen for iso phosVF2.1Cl and iso $\mathrm{VF} 2.1 \mathrm{Cl}$ with $\Delta \mathrm{F} / \mathrm{F}$ per $100 \mathrm{mV}$ values of 11 and 9\% respectively (Figure S13). No significant differences were observed in the relative brightness or signal-to-noise ratio when both para probes were loaded at $250 \mathrm{nM}$ (Figure S12), suggesting that switching from a sulfonate to a phosphonate has a negligible effect on the orientation or ability to load into cellular membranes.

\section{Conclusions}

In summary, we report the first synthesis of 3phosphonofluoresceins, characterize the spectroscopic properties of this new class of fluorophore, and use 3phosphonofluorescein in two orthogonal live-cell imaging applications. The new synthetic route to 3phosphonofluorescein provides access to unhalogenatedand 2',7'-dihalogen-3-phosphonofluoresceins. 2',7'dichloro-3-phosphonofluorescein is more water soluble than its 3-carboxy analog. In addition, 3phosphonofluoresceins, unlike 3-carboxyfluoresceins, do not spirocyclize, rendering them cell-impermeant. Esterification of the phosphonic acid allows delivery of 3phosphonofluoresceins to living cells, where they show an almost 70-fold increase in cellular brightness over carboxy 
fluorescein as a result of improved accumulation and retention. Finally, we adapt the synthesis of 3phosphonofluoresceins to include 5- or 6-bromo derivatives en route to voltage-sensitive 3phosphonofluoresceins. These new phosVF dyes show excellent membrane staining and have voltage sensitivity rivaling the best fluorescein-based VF dyes. ${ }^{60}$ We imagine that 3-phosphonofluoresceins will be of utility for longterm imaging applications that rely on a high degree of cellular retention and in voltage imaging applications. We envision that 3-phosphono substitution will yield additional opportunities in the context of xanthene dyes like rhodamines, and studies towards this end are underway in our lab.

\section{ASSOCIATED CONTENT}

Supporting Information. Supplementary data, including supporting figures, spectra, procedures, and analysis. This material is available free of charge via the Internet at http://pubs.acs.org.

\section{AUTHOR INFORMATION}

\section{Corresponding Author \\ *evanwmiller@berkeley.edu}

\section{ACKNOWLEDGMENT}

E.W.M. acknowledges generous support from the University of California, Berkeley, Klingenstein-Simons Fellowship in the Neuroscience, Camille Dreyfus Teacher-Scholar Fellowship, and the National Institute for General Medical Sciences (R35 GM119855). B.R.D. was supported, in part, by a training grant from NIGMS (T32GM666098).

\section{REFERENCES}

1. Baeyer, A., Ueber eine neue Klasse von Farbstoffen. Berichte der deutschen chemischen Gesellschaft 1871, 4 (2), 555558.

2. Coons, A. H.; Creech, H. J.; Jones, R. N.; Berliner, E., The Demonstration of Pneumococcal Antigen in Tissues by the Use of Fluorescent Antibody. The Journal of Immunology 1942, 45 (3), 159.

3. Clark Brelje, T.; Wessendorf, M. W.; Sorenson, R. L., Chapter 5 - Multicolor Laser Scanning Confocal Immunofluorescence Microscopy: Practical Application and Limitations. In Methods in Cell Biology, Matsumoto, B., Ed. Academic Press: 2002; Vol. 70, pp 165-249e.

4. Wilson, S. A.; Last, A., Management of corneal abrasions. American family physician 2004, 70 (1), 123-8.

5. Marmor, M. F.; Ravin, J. G., Fluorescein angiography: insight and serendipity a half century ago. Archives of ophthalmology (Chicago, Ill. : 1960) 2011, 129 (7), 943-8.

6. Cavallo, C.; De Laurentis, C.; Vetrano, I. G.; Falco, J.; Broggi, M.; Schiariti, M.; Ferroli, P.; Acerbi, F., The utilization of fluorescein in brain tumor surgery: a systematic review. Journal of neurosurgical sciences 2018, 62 (6), 690-703.

7. Johnson, I. D., Molecular Probes Handbook: A Guide to Fluorescent Probes and Labeling Technologies. Life Technologies Corporation: 2010.

8. Lavis, L. D.; Raines, R. T., Bright Building Blocks for Chemical Biology. ACS Chemical Biology 2014, 9 (4), 855-866.

9. Lavis, L. D., Teaching Old Dyes New Tricks: Biological Probes Built from Fluoresceins and Rhodamines. Annual Review of Biochemistry 2017, 86 (1), 825-843.
10. Urano, Y.; Kamiya, M.; Kanda, K.; Ueno, T.; Hirose, K.; Nagano, T., Evolution of Fluorescein as a Platform for Finely Tunable Fluorescence Probes. Journal of the American Chemical Society 2005, 127 (13), 4888-4894.

11. Miura, T.; Urano, Y.; Tanaka, K.; Nagano, T.; Ohkubo, K.; Fukuzumi, S., Rational Design Principle for Modulating Fluorescence Properties of Fluorescein-Based Probes by Photoinduced Electron Transfer. Journal of the American Chemical Society 2003, 125 (28), 8666-8671.

12. Grimm, J. B.; Heckman, L. M.; Lavis, L. D., The chemistry of small-molecule fluorogenic probes. Progress in molecular biology and translational science 2013, 113, 1-34.

13. Minta, A.; Kao, J. P.; Tsien, R. Y., Fluorescent indicators for cytosolic calcium based on rhodamine and fluorescein chromophores. The Journal of biological chemistry 1989, 264 (14), 8171-8.

14. Gee, K. R.; Brown, K. A.; Chen, W. N. U.; Bishop-Stewart, J.; Gray, D.; Johnson, I., Chemical and physiological characterization of fluo-4 Ca2+-indicator dyes. Cell Calcium 2000, 27 (2), 97-106.

15. Roopa; Kumar, N.; Kumar, M.; Bhalla, V., Design and Applications of Small Molecular Probes for Calcium Detection. Chemistry - An Asian Journal 2019, 14 (24), 4493-4505.

16. Beija, M.; Afonso, C. A. M.; Martinho, J. M. G., Synthesis and applications of Rhodamine derivatives as fluorescent probes. Chemical Society Reviews 2009, 38 (8), 2410-2433.

17. Grimm, J. B.; English, B. P.; Chen, J.; Slaughter, J. P.; Zhang, Z.; Revyakin, A.; Patel, R.; Macklin, J. J.; Normanno, D.; Singer, R. H.; Lionnet, T.; Lavis, L. D., A general method to improve fluorophores for live-cell and single-molecule microscopy. Nature methods 2015, 12 (3), 244-50, 3 p following 250.

18. Grimm, J. B.; Sung, A. J.; Legant, W. R.; Hulamm, P.; Matlosz, S. M.; Betzig, E.; Lavis, L. D., Carbofluoresceins and Carborhodamines as Scaffolds for High-Contrast Fluorogenic Probes. ACS Chemical Biology 2013, 8 (6), 1303-1310.

19. Grimm, J. B.; Gruber, T. D.; Ortiz, G.; Brown, T. A.; Lavis, L. D., Virginia Orange: A Versatile, Red-Shifted Fluorescein Scaffold for Single- and Dual-Input Fluorogenic Probes. Bioconjugate Chemistry 2016, 27 (2), 474-480.

20. Fu, M.; Xiao, Y.; Qian, X.; Zhao, D.; Xu, Y., A design concept of long-wavelength fluorescent analogs of rhodamine dyes: replacement of oxygen with silicon atom. Chemical Communications 2008, (15), 1780-1782.

21. Egawa, T.; Koide, Y.; Hanaoka, K.; Komatsu, T.; Terai, T.; Nagano, T., Development of a fluorescein analogue, TokyoMagenta, as a novel scaffold for fluorescence probes in red region. Chemical Communications 2011, 47 (14), 4162-4164.

22. Hirabayashi, K.; Hanaoka, K.; Takayanagi, T.; Toki, Y.; Egawa, T.; Kamiya, M.; Komatsu, T.; Ueno, T.; Terai, T.; Yoshida, K.; Uchiyama, M.; Nagano, T.; Urano, Y., Analysis of Chemical Equilibrium of Silicon-Substituted Fluorescein and Its Application to Develop a Scaffold for Red Fluorescent Probes. Analytical Chemistry 2015, 87 (17), 9061-9069.

23. Grimm, J. B.; Brown, T. A.; Tkachuk, A. N.; Lavis, L. D., General Synthetic Method for Si-Fluoresceins and Si-Rhodamines. ACS Central Science 2017, 3 (9), 975-985.

24. Fukazawa, A.; Usuba, J.; Adler, R. A.; Yamaguchi, S., Synthesis of seminaphtho-phospha-fluorescein dyes based on the consecutive arylation of aryldichlorophosphines. Chemical Communications 2017, 53 (61), 8565-8568.

25. Zhou, X.; Lai, R.; Beck, J. R.; Li, H.; Stains, C. I., Nebraska Red: a phosphinate-based near-infrared fluorophore scaffold for chemical biology applications. Chemical Communications 2016, 52 (83), 12290-12293.

26. Chai, X.; Cui, X.; Wang, B.; Yang, F.; Cai, Y.; Wu, Q.; Wang, T., Near-Infrared Phosphorus-Substituted Rhodamine with Emission Wavelength above $700 \mathrm{~nm}$ for Bioimaging. Chemistry - A European Journal 2015, 21 (47), 16754-16758.

27. Liu, J.; Sun, Y.-Q.; Zhang, H.; Shi, H.; Shi, Y.; Guo, W., Sulfone-Rhodamines: A New Class of Near-Infrared Fluorescent 
Dyes for Bioimaging. ACS Applied Materials \& Interfaces 2016, 8 (35), 22953-22962.

28. Uno, S.-n.; Kamiya, M.; Yoshihara, T.; Sugawara, K.; Okabe, K.; Tarhan, M. C.; Fujita, H.; Funatsu, T.; Okada, Y.; Tobita, S.; Urano, Y., A spontaneously blinking fluorophore based on intramolecular spirocyclization for live-cell super-resolution imaging. Nature Chemistry 2014, 6 (8), 681-689.

29. Uno, S. N.; Kamiya, M.; Morozumi, A.; Urano, Y., A greenlight-emitting, spontaneously blinking fluorophore based on intramolecular spirocyclization for dual-colour super-resolution imaging. Chemical communications (Cambridge, England) 2017, 54 (1), 102-105.

30. Zheng, Q.; Ayala, A. X.; Chung, I.; Weigel, A. V.; Ranjan, A.; Falco, N.; Grimm, J. B.; Tkachuk, A. N.; Wu, C.; Lippincott-Schwartz, J.; Singer, R. H.; Lavis, L. D., Rational Design of Fluorogenic and Spontaneously Blinking Labels for Super-Resolution Imaging. ACS Central Science 2019, 5 (9), 1602-1613.

31. Miller, E. W.; Lin, J. Y.; Frady, E. P.; Steinbach, P. A.; Kristan, W. B.; Tsien, R. Y., Optically monitoring voltage in neurons by photo-induced electron transfer through molecular wires. Proceedings of the National Academy of Sciences 2012, 109 (6), 2114-2119.

32. Kulkarni, R. U.; Yin, H.; Pourmandi, N.; James, F.; Adil, M. M.; Schaffer, D. V.; Wang, Y.; Miller, E. W., A Rationally Designed, General Strategy for Membrane Orientation of Photoinduced Electron Transfer-Based Voltage-Sensitive Dyes. ACS Chemical Biology 2017, 12 (2), 407-413.

33. Ortiz, G.; Liu, P.; Naing, S. H. H.; Muller, V. R.; Miller, E. W., Synthesis of Sulfonated Carbofluoresceins for Voltage Imaging. Journal of the American Chemical Society 2019, 141 (16), 66316638.

34. Liu, P.; Miller, E. W., Electrophysiology, Unplugged: Imaging Membrane Potential with Fluorescent Indicators. Accounts of Chemical Research 2020, 53 (1), 11-19.

35. Remsen, I., On a new class of compounds analogous to the phthaleins. Am Chem J 1884, 6, 180-181.

36. Franz, R. G., Comparisons of pKa and log P values of some carboxylic and phosphonic acids: Synthesis and measurement. AAPS PharmSci 2001, 3 (2), 1.

37. Kovi, R.; Nampalli, S.; Tharial, P. X. Process for preparation and purification of isosulfan blue. US20080281127A1, 2008.

38. Tavs, P., Reaktion von Arylhalogeniden mit Trialkylphosphiten und Benzolphosphonigsäure-dialkylestern zu aromatischen Phosphonsäureestern und Phosphinsäureestern unter Nickelsalzkatalyse. Chemische Berichte 1970, 103 (8), 24282436.

39. Balthazor, T. M.; Grabiak, R. C., Nickel-catalyzed Arbuzov reaction: mechanistic observations. The Journal of Organic Chemistry 1980, 45 (26), 5425-5426.

40. Leonhardt, H.; Gordon, L.; Livingston, R., Acid-base equilibriums of fluorescein and 2',7'-dichlorofluorescein in their ground and fluorescent states. The Journal of Physical Chemistry 1971, 75 (2), 245-249.

41. Martin, M. M.; Lindqvist, L., The $\mathrm{pH}$ dependence of fluorescein fluorescence. Journal of Luminescence 1975, 10 (6), 381-390.

42. Sjöback, R.; Nygren, J.; Kubista, M., Absorption and fluorescence properties of fluorescein. Spectrochimica Acta Part A: Molecular and Biomolecular Spectroscopy 1995, 51 (6), L7-L21.

43. Sun, W.-C.; Gee, K. R.; Klaubert, D. H.; Haugland, R. P., Synthesis of Fluorinated Fluoresceins. The Journal of Organic Chemistry 1997, 62 (19), 6469-6475.

44. Tsien, R. Y., A non-disruptive technique for loading calcium buffers and indicators into cells. Nature 1981, 290 (5806), 527-528.
45. Lavis, L. D.; Chao, T.-Y.; Raines, R. T., Synthesis and utility of fluorogenic acetoxymethyl ethers. Chemical Science 2011, 2 (3), 521-530.

46. Prosperi, E.; Croce, A. C.; Bottiroli, G.; Supino, R., Flow cytometric analysis of membrane permeability properties influencing intracellular accumulation and efflux of fluorescein. Cytometry 1986, 7 (1), 70-5.

47. Rotman, B.; Papermaster, B. W., Membrane properties of living mammalian cells as studied by enzymatic hydrolysis of fluorogenic esters. Proceedings of the National Academy of Sciences of the United States of America 1966, 55 (1), 134-41.

48. Izumi, S.; Urano, Y.; Hanaoka, K.; Terai, T.; Nagano, T., A Simple and Effective Strategy To Increase the Sensitivity of Fluorescence Probes in Living Cells. Journal of the American Chemical Society 2009, 131 (29), 10189-10200.

49. Rusha, L.; Miller, S. C., Design and application of esteraselabile sulfonate protecting groups. Chemical Communications 2011, 47 (7), 2038-2040.

50. Schultz, C.; Vajanaphanich, M.; Harootunian, A. T.; Sammak, P. J.; Barrett, K. E.; Tsien, R. Y., Acetoxymethyl esters of phosphates, enhancement of the permeability and potency of cAMP. The Journal of biological chemistry 1993, 268 (9), 6316-22.

51. Li, W.; Schultz, C.; Llopis, J.; Tsien, R. Y., Membranepermeant esters of inositol polyphosphates, chemical syntheses and biological applications. Tetrahedron 1997, 53 (35), 1201712040 .

52. Wiemer, A. J.; Wiemer, D. F., Prodrugs of Phosphonates and Phosphates: Crossing the Membrane Barrier. In Phosphorus Chemistry I: Asymmetric Synthesis and Bioactive Compounds, Montchamp, J.-L., Ed. Springer International Publishing: Cham, 2015; pp 115-160.

53. Pradere, U.; Garnier-Amblard, E. C.; Coats, S. J.; Amblard, F.; Schinazi, R. F., Synthesis of Nucleoside Phosphate and Phosphonate Prodrugs. Chemical Reviews 2014, 114 (18), 91549218.

54. Schultz, C., Prodrugs of biologically active phosphate esters. Bioorganic \& Medicinal Chemistry 2003, 11 (6), 885-898.

55. Diehl, H.; Ellingboe, J. L., Indicator for Titration of Calcium in Presence of Magnesium Using Disodium Dihydrogen Ethylenediamine Tetraacetate. Analytical Chemistry 1956, 28 (5), 882-884.

56. Sun, H.; Johnson, D. R.; Finch, R. A.; Sartorelli, A. C.; Miller, D. W.; Elmquist, W. F., Transport of fluorescein in MDCKII-MRP1 transfected cells and mrp1-knockout mice. Biochem Biophys Res Commun 2001, 284 (4), 863-869.

57. Shugarts, S.; Benet, L. Z., The Role of Transporters in the Pharmacokinetics of Orally Administered Drugs. Pharmaceutical Research 2009, 26 (9), 2039-2054.

58. Gekeler, V.; Ise, W.; Sanders, K. H.; Ulrich, W. R.; Beck, J., The leukotriene LTD4 receptor antagonist MK571 specifically modulates MRP associated multidrug resistance. Biochem Biophys Res Commun 1995, 208 (1), 345-52.

59. Deal, P. E.; Kulkarni, R. U.; Al-Abdullatif, S. H.; Miller, E. W., Isomerically Pure Tetramethylrhodamine Voltage Reporters. Journal of the American Chemical Society 2016, 138 (29), 90859088.

60. Boggess, S. C.; Lazzari-Dean, J. R.; Raliski, B. K.; Mun, D. M.; Li, A. Y.; Turnbull, J. L.; Miller, E. W., Fluorescence lifetime predicts performance of voltage sensitive fluorophores in cardiomyocytes and neurons. RSC Chemical Biology 2021. 
Phosphono-fluoresceins: synthesis and applications
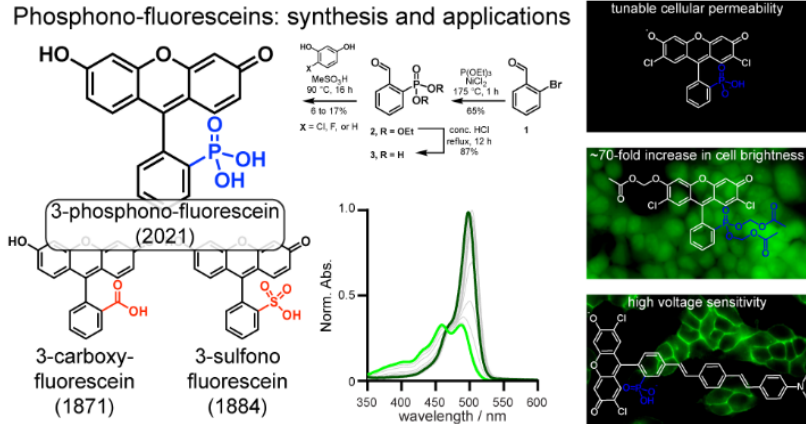